\title{
POLICY ENVIRONMENT AND PUBLIC SERVICE MOTIVATION
}

\section{SIMON ANDERFUHREN-BIGET, FRÉDÉRIC VARONE AND DAVID GIAUQUE}

This article analyzes whether and to what extent the policy environment of civil servants has an impact on their level of Public Service Motivation (PSM). It hypothesizes that public employees working in different policy domains and stages of the policy cycle are diversely motivated by four PSM orientations (Compassion, Commitment to the public interest, Self-sacrifice and Attraction to politics). The empirical results are based on a survey of 6885 Swiss civil servants. They show that those in charge of Welfare State policies are inclined to have higher levels of 'Compassion', whereas those performing core state functions report lower levels. Furthermore, employees whose main tasks are related to policy formulation display high levels of the 'Attraction to politics' dimension of PSM. This study questions the generalization of previous findings on PSM that are based on heterogeneous survey populations.

\section{INTRODUCTION}

The Public Service Motivation (PSM) approach claims that public servants have a sense of public interest and are committed to the concerns of others. Empirical studies measuring PSM levels, antecedents, and outcomes have investigated very different and, at the same time, very specific samples of civil servants. On the one hand, some analyze rather homogeneous populations such as Korean firefighters (Kim 2011), Danish health practitioners (Andersen 2009), Belgian or North American undergraduates (Clerkin et al. 2009; Vandenabeele 2008), winners of volunteering awards (Perry et al. 2008), Italian tax experts (Cerase and Farinella 2009), or Chinese social workers (Bangcheng 2009). On the other hand, heterogeneous samples in terms of policy sectors and occupational groups were researched (i.e. Bright 2009; Kim 2006; Perry 1996, 1997; Vandenabeele 2009). Notably, these studies do not discuss in depth any discernible differences between policy sectors, and observed levels of PSM are set forth as if the entire public sector was a homogeneous field.

In contrast to this research trend, and in keeping with a long tradition of public policy analysis, the public sector is better characterized by heterogeneity (i.e. public service missions, policy tasks, organizational contexts, and working conditions). It thus makes sense to question the relevance of comparing empirical data from such highly contrasting situations and, furthermore, whether general conclusions can be drawn from such comparisons.

This article addresses this theoretical issue by systematically analyzing the potential relationships between policy-related factors and the PSM level of public employees. Our main goal is to couple the PSM approach with some of the basic concepts of classical policy analysis. Rather than discussing all of the facets of the public policy perspective in this article, we focus on two main dimensions characterizing the context of any public policy: the peculiarities of the policy sectors (or domains), and the main responsibilities of the civil servant regarding the stages (or sequences) of the policy cycle. This article thus

Simon Anderfuhren-Biget is a research assistant at the University of Geneva. Frédéric Varone is Professor of Political Science at the University of Geneva. David Giauque is Professor at the University of Lausanne and a member of the Institute of Political and International Studies. 
combines the individual-level, management-oriented PSM construct with a meso-level approach for scrutinizing state action in specific policy sectors and during particular policy stages.

Empirically, this study assesses the relations between the policy domains and policy sequences in which civil servants work, on the one hand, and the four motivational orientations embedded in the PSM concept on the other. The rationales are based on the Attraction-Selection-Attrition framework, a refinement of the greater Person-Environment fit paradigm, which stipulates that 'certain types of people are attracted to, and prefer, particular types of organizations; organizations formally and informally select certain types of people to join the organization; and attrition occurs when people who do not fit a particular organization leave' (Schneider et al. 2000, p. 67). As public service motivated employees hold particular values - since PSM is a value-laden concept at the individual level - they are more likely to seek and keep positions in the public sector that are congruent with what they valorize.

In this article, we aim to answer the following research question: Does a civil servant's level of PSM relate to the policy domain and/or the policy stage in which he/she is involved? In terms of PSM research, this investigation responds to several calls to elucidate how PSM levels are distributed amongst the various tasks endorsed by different public employees (among them: Pandey and Stazyk 2008). Our argument is presented in four steps. The theoretical section defines the dependent variable (i.e. level of PSM) and the independent variables (i.e. policy sectors and stages of the policy cycle), as well as the research hypotheses. The sample is described as well as the measure and statistical strategy in the methodological section. The subsequent section presents the results of the analyses in two steps (i.e. mean differences analysis and regression model). Finally, the implications of these results are discussed in the concluding section.

\section{THEORY: LINKING POLICY ENVIRONMENT AND PUBLIC SERVICE MOTIVATION}

A public policy may be defined as a series of decisions and actions taken by public authorities to resolve a public problem (e.g. pollution, unemployment, price instability, urban violence, gender inequality) that is identified as a priority on the political agenda (Knoepfel et al. 2007). Such state responses are designed and implemented by professionals working in various policy sectors (e.g. security) and their corresponding public administrations and agencies (e.g. Ministry of the Interior). Before turning to the variables characterizing the policy context in which civil servants are embedded (i.e. policy sectors and stages), we discuss the definition and dimensionality of PSM, as well as the strategies undertaken to unveil its explanatory factors.

\section{Understanding PSM and its fostering factors}

To be clear, PSM is neither an exclusive feature of public employees nor is it the only motivational factor of public employees (Anderfuhren-Biget et al. 2010; Perry and Hondeghem 2008). Accordingly, the PSM inclination can be understood as a particular sense of commitment to 'public service values' that can in turn be endorsed by organizations of different types. PSM thus circumscribes 'the beliefs, values and attitudes that go beyond self-interest and organizational interest, that concern the interest of a larger political entity and that motivate individuals to act accordingly whenever appropriate' (Vandenabeele 2007 , p. 20). For an overview of the definitions, see Perry et al. (2010). 
Empirically, Perry (1996) made the first attempt at creating a measurement scale after which PSM has comprised four sub-dimensions. Attraction to politics characterizes public employees who prefer to serve the public interest by influencing political processes or those who are particularly interested in the political sphere. Commitment to the public interest describes civil servants' aspirations for pursuing the common good and furthering the public interest (i.e. achieving policy goals). Compassion is a unique feeling of sympathy for the suffering of others that involves emotions and empathy towards others (i.e. target groups of a given public policy), a sense of understanding, and the drive to protect. Selfsacrifice or 'willingness to substitute service to others for tangible personal rewards' (Perry 1996, p. 6) is characterized by a devotional desire to help others and a sense of abnegation.

This combination has the advantage of covering most of the motivational particularities of public service by encompassing diversified motivational inclinations (Bright 2009; Vandenabeele 2009). For instance, compassionate public servants do not necessarily show a high level of 'Attraction to politics' and vice versa. Therefore, we expect that the four PSM dimensions will be differentially related to the policy variables investigated here. In so doing, we are also following recent articles that recommend the operationalization of the four PSM dimensions as separate components, as such specification dovetails with the original conceptualization of PSM (Kim 2011), and is empirically coherent as the different PSM orientations are diversely related to attitudinal outcomes like resigned satisfaction (Giauque et al. 2012). Concretely, we posit that the different policy domains and stages of the policymaking process attract, select, or retain individuals having different PSM motivational orientations. Consequently, we analyze how they are differentially related to the policy environment of civil servants.

Different strategies have been used to identify the factors related to PSM, but most have not considered the policy environment as a relevant feature. Conversely, PSM scholars have principally directed their attention towards individual, institutional, organizational, or sociopolitical factors. For instance, it can be assumed that a high level of PSM is more likely to be found among well-educated older men (for an overview of individual antecedents, see Pandey and Stazyk 2008). Family, religion, and professions were originally identified as the institutions fostering PSM (Perry 1997). Parental modelling, either as altruistic exemplars (Perry 1997; Perry et al. 2008), or as public service exemplars (Vandenabeele 2011), also has a positive effect on PSM. A sense of spirituality and a belief in transcendence seem to be closely related to public service work, as well as volunteering behaviours (Houston and Cartwright 2007; Perry et al. 2008).

In contrast to these robust results, no definitive statement can be made regarding how professions can determine PSM (Moynihan and Pandey 2007; Perry 1997). The results on how organizational membership predicts PSM are also rather mixed (Camilleri 2007; Castaing 2006; Moynihan and Pandey 2007; Naff and Crum 1999; Steijn 2006). However, hierarchical level (Camilleri 2007; Moynihan and Pandey 2007), encouraging job features (Camilleri 2007; Park and Rainey 2007), a constructive relationship with leadership (Camilleri 2007; Park and Rainey 2007), and a positive perception of the organization (Camilleri 2007) are all strong predictors of PSM. In a nutshell, different organizational practices have the potential to enhance or undermine PSM (Anderfuhren-Biget et al. 2010; Giauque et al. 2013). Finally, social capital factors (e.g. associational involvement, social trust, or political participation) as well as differences in cultural belonging also contribute to the explanation of PSM level (Anderfuhren-Biget 2012).

To the best of our knowledge, only two studies have, in some ways, explicitly addressed the heterogeneity of the policy environment as a correlate of PSM (Castaing 2006; Leisink 
and Steijn 2009). Both studies' results are discussed below in relation to the relevant dimensions of the policy environment.

\section{Heterogeneity of the administrative system and motivational patterns}

This article discusses the expected relationships between two characteristics of the policy environment as independent variables, and the individual level of PSM as a dependent variable. However, this causality could be reversed as the theoretical approach suggests that policy environment is both a determinant of PSM level (i.e. attraction process) and a consequence of PSM level (i.e. attrition and homogenization processes). We thus focus more on the strength of the relationship than on the direction of the causality.

Policy sectors are defined by the distinctiveness of the collective problems addressed and the policy network of actors. In other words, '(policy) sectors are organizational structures, as identifiable (and impermeable) as institutions, and have their own rules, customs and internal hierarchies' (John and Cole 2000, p. 249). In this respect, they constitute semi-autonomous areas of state action and communities of actors who share common frames or 'policy images' that are composed, among other things, of particular norms and values. This plurality of values (Pesch 2008, p. 335; cited by Van der Wal and Van Hout 2009, p. 223) is crucial to understanding policymaking processes (John and Cole 2000), as well as the multiple and sometimes conflicting goals pursued by the state in various policy sectors (Rainey 2009).

Furthermore, a public policy is frequently presented as a cyclical process involving phases of agenda-setting, policy formulation, policy implementation, and, ultimately, evaluation of policy outcome. This overly simplistic description of policymaking processes provides a valuable heuristic device (Jann and Wegrich 2007) and allows for a clearer distinction of the concrete tasks performed by civil servants, as well as their formal competences and responsibilities. Hereafter, we focus on both policy domains and phases, and their expected relationships with individual levels of PSM.

\section{Policy sectors and PSM}

Lowi (1964) has argued that sector-specific issues determine the style of decision-making and the type of political conflict, not vice versa. This perspective was further developed by mainstream policy scholars who then focused on policy sectors or subsystems, which are characterized by a stabilized network of actors and a common cognitive frame. According to the Advocacy Coalition Framework (ACF) developed by Sabatier and Jenkins-Smith (1993, 1999; see also Weible et al. 2009, p. 192), distinct policy subsystems are composed of competing coalitions whose members include legislators, public administrations, interest groups, researchers, and journalists. These advocacy coalitions represent a relatively integrated policy community built upon a common 'belief system' (Sabatier and JenkinsSmith 1993, 1999).

The policy subsystems thus emerge and stabilize throughout the framing of policy problems to be solved, the division of labour between public administrations, the action of sector-specific interest groups, the production of professional knowledge, and the allocation of the public budget between sector-specific programmes (Freeman 1985, p. 483). Furthermore, public administrations participate in such policy subsystems with the aim of influencing the respective public policies over a fairly long period of time (Sabatier and Jenkins-Smith 1999, p. 136).

For the cognitive approach to policy analysis, 'frames of reference' or 'belief systems' are shared among the different actors of a policy sector. Accordingly, if each policy 
sector is characterized by a specific actors' network (including public employees) and a specific cognitive frame (including fundamental values and policy beliefs), then it is worth looking at how previous PSM empirical studies have taken into account such specifications. Of course, the variety of policy sectors is not always systematically scrutinized, and this is not a fatal flaw since each study has its own purpose that is unrelated to the present line of enquiry.

Bright, for example, published two studies using a highly diversified sample of local government employees (building inspectors, community health workers, sheriffs, caseworkers, secretaries, district attorneys, librarians, maintenance workers, detectives, and juvenile counsellors), but did not explicitly address this extraordinary diversity (Bright 2005, 2009). The same criticism applies to Vandenabeele's study on Flemish state employees (Vandenabeele 2009), as well as several others (i.e. Alonso and Lewis 2001; Camilleri 2007; Perry 1996, 1997). Conversely, to the best of our knowledge, Leisink and Steijn have published the only study comparing different policy sectors (general administration, public security, defence, education, and academic hospitals), which shows rather thin differences in mean levels of PSM dimensions (Leisink and Steijn 2009, pp. 43-44).

\section{Stages of the policy cycle and PSM}

The 'policy cycle approach' is a heuristic and sequential representation of public policy rather than a rigid grid (for a general presentation of the approach, see Jones 1984; for a more recent critic of the model, see Sabatier and Jenkins-Smith 1993). The policy formulation and implementation phases are obviously the most relevant for our research purposes. As a matter of fact, the role and influence of civil servants are greater in these two intermediate and well-institutionalized phases than they are in the agenda-setting and evaluation phases which are open to all policy actors. Furthermore, one can hardly imagine that a civil servant would be involved only in the agenda-setting phase without also taking part in the subsequent policy formulation stage. In a similar vein, public employees who are in charge of conducting a policy evaluation have generally also been in charge of (parts of) the implementation of previous policies. All in all, we suggest that the policy cycle be divided into two main stages: policy formulation and policy implementation, while employees working for internal services should mostly perform tasks supporting the smooth running of the policymaking process.

This sequential approach offers several advantages for policy scholars, including the identification of the stakes and actors involved in each stage of the policy cycle. It is also particularly relevant for PSM studies insofar as one might expect that civil servants involved in various policy stages will have potentially different motivational features inherent to their positions within the decision-making process and/or their professional roles (Rouban 1995). For instance, it can be assumed that individuals who have an interest in political affairs seek jobs that are likely to support such preferences (i.e. policy formulation).

Despite this link between actors' roles during the policymaking process and PSM values, few empirical studies have addressed this issue by crossing the policy cycle approach characterizing performed tasks and the four PSM orientations. Although Castaing's empirical analysis is not exactly in line with our objectives, as the author refers to the very French 'Corps' categorization, it nonetheless shows the greater importance of 'Commitment to the public interest' for public servants responsible for policy formulation than for those in charge of internal services provision (Castaing 2006, p. 93). 
The present study goes one step further. As it is based on a sample of Swiss public employees working within four policy subsystems besides general administration (welfare, public utilities, environment and infrastructure, and core state functions) and performing policy formulation and implementation tasks, it allows for the systematic assessment of the relationships between the two policy variables (domains and stages) and the four dimensions of PSM.

\section{Research hypotheses}

Our brief literature review shows that previous studies on the (hypothetical) links between policy environment and PSM levels are sparse and inconclusive. However, one of the basic postulates of PSM theory expects a positive association between PSM level and the willingness to join a public organization (Perry and Wise 1990). This primary expectation received several empirical confirmations (Leisink and Steijn 2008; Lewis and Frank 2002; Vandenabeele 2008; Vandenabeele et al. 2004; Wright and Christensen 2010). Nevertheless, as PSM is constituted by four sets of motivational values ('Attraction to politics', 'Commitment to the public interest', 'Compassion', and 'Self-sacrifice'), and because the public sector is characterized by heterogeneity in terms of policy sectors and stages of the policy cycle, one might legitimately wonder how employees with such specific values can find jobs in a congruent policy environment. It is therefore relevant to ask whether and to what extent the motivation of civil servants is related to the specificities of their respective environments.

To answer this question, we formulate an initial set of research hypotheses whose rationales rely on the Person-Environment $(\mathrm{P}-\mathrm{E})$ fit. This framework postulates that individuals are willing to work in value congruent environments (Edwards et al. 2006). We also rely on Attraction-Selection-Attrition (ASA) processes that lead to a homogenization of the staff values and additional personality traits (Schneider et al. 1995). Accordingly, individuals join organizations involved in specific policy domains, and specific jobs (i.e. policy tasks performed) that they expect to be congruent with their own value systems. Such expected relations are particularly appropriate for the Swiss administrative context (empirically investigated here), as it is not a career system. Consequently, applicants for jobs in public administration have full knowledge and understanding of the policy domain, the tasks performed, and the administrative functions for which they apply (Varone 2007).

Both theoretical frameworks (i.e. P-E fit and ASA) support the expectation that the policy environments of civil servants are related to their respective PSM levels. The direction of the causality between the characteristics of the policy environment and the level of PSM cannot be definitively demonstrated with our methodological design. However, this is not a major problem per se, as the P-E fit and the ASA frameworks are compatible with both directions of causality. Hence, PSM can be seen either as a cause or a consequence of employment choice. PSM is viewed as a determinant of policy environment preference if one considers attraction processes, while PSM is an outcome if one focuses on staff selection and the homogenization of staff values.

The present empirical study will not overcome this causality issue, although it systematically assesses the relationships between PSM dimensions and core features of the policy environment of civil servants. Such an empirical analysis is relevant, as however the issue is argued (i.e. PSM as cause or consequence of policy environment), a strong relation between both variables can eventually be expected.

As we have previously noted, policy environments are permeated by structuring frames of reference or values that are common to the different actors involved in a public policy 
TABLE 1 Specific dimensional hypotheses

\begin{tabular}{|c|c|c|c|}
\hline & PSM dimensions & Hypothesis & Theory \\
\hline \multicolumn{4}{|l|}{ Policy domains } \\
\hline \multirow[t]{3}{*}{ Welfare } & (+) Compassion & H1a & ASA; Vinzant, 1998 \\
\hline & (+) Commitment to the public interest & $\mathrm{H} 1 \mathrm{~b}$ & Vinzant, 1998 \\
\hline & (+) Self-sacrifice & $\mathrm{H} 1 \mathrm{c}$ & ASA \\
\hline Core state functions & (-) Compassion & $\mathrm{H} 2$ & ASA \\
\hline Public utilities & (+) Commitment to the public interest & $\mathrm{H} 3$ & ASA \\
\hline \multicolumn{4}{|l|}{ Phase of policy cycle } \\
\hline \multirow[t]{2}{*}{ Formulation } & (+) Attraction to politics & $\mathrm{H} 4 \mathrm{a}$ & ASA \\
\hline & (+) Commitment to the public interest & $\mathrm{H} 4 \mathrm{~b}$ & Castaing, 2006 \\
\hline \multirow[t]{2}{*}{ Implementation } & (+) Compassion & H5a & ASA \\
\hline & (+) Commitment to the public interest & $\mathrm{H} 5 \mathrm{~b}$ & Pandey and Stazyk, 2008 \\
\hline
\end{tabular}

and that transcend governmental levels. Thus, this study expects the different policy domains (General Administration, Welfare, Public Utilities, Core State Functions) or tasks along the policy cycle (Policy Formulation, Policy Implementation, Internal Services) to attract, select, and retain civil servants for whom the different PSM orientations are part of what they valorize and seek to pursue based on their congruent needs. With regard to the absence of a detailed literature that combines the PSM and policy analysis perspectives, this general expectation can be further differentiated in an exploratory manner. Five specific detailed hypotheses are presented in table 1.

A first set of specific hypotheses is developed upon the aforementioned frameworks that expect value congruence between policy domains or phase of the policy cycle and PSM dimensions. A second set of hypotheses is drawn to test previous theoretical developments or verify previous study results with a more comprehensive design.

For instance, an employee working in the welfare sector (health, education, social work) is more likely to endorse 'Compassion' or 'Self-sacrifice' PSM orientation with regard to its constitutive missions, which have much do to with empathetic feelings for the needs of others. Such an expectation is empirically supported by findings on social workers, a professional group prone to exhibiting 'Compassion' or 'Commitment to the public interest' (Vinzant 1998). Thus: Civil servants working in the welfare sector have a higher level of 'Compassion' (H1a) and of 'Commitment to the public interest'(H1b), and 'Self-sacrifice' (H1c), respectively, than the others. Turning now to the principal values of a given policy domain, it is quite straightforward to expect that compassion is not a defining value of civil servants performing core state tasks in relation to policing or justice, for example. Therefore: Civil servants working in core state functions have a lower level of 'Compassion' than civil servants working in other sectors (H2).

Following the same reasoning, civil servants working in the public utilities domain that comprises environmental, infrastructure, or public transportation management and provision are characterized more by technical expertise than by particular driving motives. On the contrary, these domains that can be defined as being part of the 'regulatory state' are greatly subject to adjudication between private and public interests (Levi-Faur 2005; Majone 1997). In this sense, civil servants in this sub-field of political action are required to choose and develop public policies that seek to achieve the public interest. Consequently: Civil servants working in the utilities sector have a higher level of 'Commitment to the public interest' than civil servants working in other sectors (H3). 
Regarding the formulation phase of the policymaking process, we can presuppose that civil servants who formulate and design public policies are likely to be interested in political affairs as they operationalize political choices and trade-offs, and are directly relating to elected politicians who are their principals. These employees are aware that political choice is a matter of value allocation and priorities. They want to control the policy agenda and have clear and defined political values or ideologies that they seek to serve by influencing the construction of public problems or by participating in the definition of the objectives of a given public policy. Furthermore, Castaing found that civil servants responsible for policy formulation have a higher level of 'Commitment to the public interest' (positive association) than civil servants in charge of internal services provision (negative association) (Castaing 2006, p. 93). On the basis of an anticipated convergence of interests, as well as on previous empirical findings, we expect that: Civil servants in charge of policy formulation have a higher level of 'Attraction to politics' $(\mathrm{H} 4 a)$, with respect to 'Commitment to the public interest', than the others $(\mathrm{H} 4 \mathrm{~b})$.

For the implementation phase, the reasoning is similar. Civil servants in charge of the execution of political choices are likely to be in direct contact with the targeted groups and thus have the opportunity to develop empathy and 'Compassion' for them. As they are close to their subjects, Pandey and Stazyk have suggested that street-level bureaucrats, or the public employees that are directly in contact with the beneficiaries of public policies, who represent a sub-category of implementers in the case of this study, have a greater sense of 'Commitment to the public interest' (Pandey and Stazyk 2008, pp. 113-14). Therefore: Civil servants in charge of policy implementation have a higher level of 'Compassion' $(\mathrm{H} 5 \mathrm{a})$, with respect to 'Commitment to the public interest', than the others (H5b).

\section{EMPIRICAL FIELD, MEASURES, AND METHOD}

\section{Description of the sample}

This study uses quantitative survey data of municipal and cantonal civil servants in Switzerland. With the exception of the Italian-speaking municipalities and cantons, all potential subjects received an invitation to participate in a survey. In the end, 279 municipalities and nine cantons decided to participate in the study. Depending on their preferences, administrative unit managers could choose between an online or paperbased survey. They were responsible for the distribution of the questionnaire and for the provision of basic statistics (number of employees, percentages of male and female, supervisory and non-supervisory employees, etc.) to accurately assess the response rate and the representativeness of the sample.

At the end of this process, the survey was given to 10,150 cantonal civil servants who returned 3131 questionnaires (response rate of 30.85 per cent) and to 9852 municipal civil servants, from whom 3754 questionnaires were returned (response rate of 38.1 per cent). Table 2 provides the socio-demographic description of the data. However, for the correlation and regression analyses, we proceeded with a listwise treatment of the missing values, thus ending with a slightly reduced sample constituting 5894 civil servants.

\section{Operationalization of the concepts}

\section{Public Service Motivation}

Measuring PSM is a 'hot topic' for public management scholars (Wright 2008). In this study, Perry's (1996) multidimensional measure was taken as the baseline. We reduced the set of items to a 14-item scale including items for all four PSM dimensions. The items were 
TABLE 2 Description of the sample

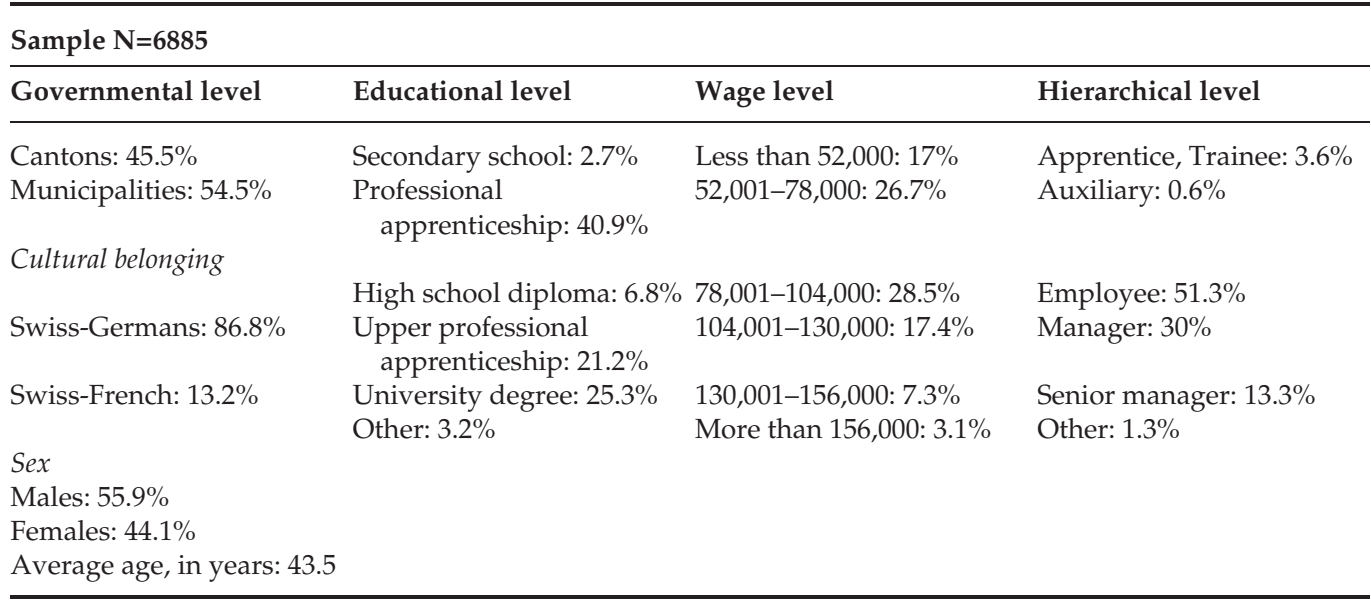

chosen based on previous research on the psychometric testing of the PSM scale. They are relevant specifically for the Swiss context. Hence, given the controversies surrounding the political dimension of PSM (Kim 2009; Ritz 2011), it was operationalized by asking how public servants are interested in political bargaining and how they like to discuss political subjects (for details on the items and their contextualization, see Giauque et al. 2011).

Five scales were thus computed to measure PSM as a whole and its four constituent dimensions. To genuinely reflect the formative nature of the composite construct of PSM, and given the fact that not all dimensions are measured with the same number of items, the general scale was computed as the mean of the four dimensions (Kim 2011). Cronbach's coefficients of reliability are rather low (PSM $=0.557$, 'Attraction to politics' $=0.917$, 'Commitment to the public interest' $=0.636$, 'Compassion' $=0.667$ and 'Self-sacrifice' $=0.552$ ), but stayed within the range of previous studies.

\section{Policy sectors}

To verify whether PSM is influenced by features related to policy domains, we asked our respondents to declare their sector of occupation and presented them with 11 possibilities, each representing examples of professions and working fields or administrative services. These were combined into four clusters of policy domains: Welfare (health, social, education, and youths); Public utilities, infrastructures and environment (network industries, environment, agriculture, energy, public transportation, and mobility); Core state functions (security, institutions, legal services, and justice); and General administration (public finances and general administration). For details, see Appendix 1. Practically, for the mean level analysis, a categorical variable with these four eventualities was created, where for the regression models, dummy variables were used $(1=$ belonging to the policy sector and $0=$ not belonging to the policy sector), with 'General administration' as the reference category.

\section{Stages of the policy cycle}

To empirically assess the location of our respondents within the policy cycle, we asked them what their principal type of task was. Three possibilities were offered. The first 
relates to agenda-setting and the formulation of public policy. We provided examples of administrative services or hierarchical level where the decisions and the political files are prepared: planning services; direction of administrative services; secretary-general; and staff headquarters. The second possibility relates to policy implementation. Specifying that this category is a matter of service delivery to users, we proposed the following illustrations of tasks: benefits or subsidies provisioning; norm enforcement; authorization granting; or user counselling.

Finally, the third possibility concerned the provision of internal services to support the work of the administration. Cases were also proposed to guide the respondents: accountability of human resource services; information and communication technology; or legal advice to support administrative tasks. Practically, for the mean analysis, a categorical variable with these three eventualities was created, where for the regression models, dummy variables were used $(1=$ policy formulation, $0=$ no policy formulation; $1=$ policy implementation, $0=$ no policy implementation), with 'Internal services' as the reference category.

\section{Socio-demographics}

To maintain comparability with previous studies, the usual socio-demographic variables (Pandey and Stazyk 2008) constitute, alongside Swiss specificities, the baseline model: gender (female $=0$; male $=1$ ); age (in years); educational, hierarchical, and wage levels; cultural belonging ( $0=$ Swiss-French; $1=$ Swiss-German); and level of governance ( $0=$ municipalities; $1=$ cantons).

\section{Methodological strategy}

This study proceeds with a set of analyses that recalls elements of the policy environment in the PSM equation. To reveal PSM levels variations among policy sectors and stages, two complementary lines of inquiry were considered. First, we compare the mean levels of the four constituent dimensions of PSM, taking into account different policy domains and stages. One-way analysis of variance and F-test attest to significant differences (Sirkin 2006). Coefficient $\mathrm{Eta}^{2}$ testifies to the amount of variance in PSM and its dimensions that is accounted for by the selected variables. After the comparative analysis, an encompassing model of regressions is tested to reveal the pure effect of the two variables that are studied and their outcomes. It consists of a three-step model of regressions. The first step is the baseline model (socio-demographic and context-relevant variables) wherein the second and third steps analyze how the different policy domains and the respective phases of the policy cycle are related to PSM.

\section{RESULTS OF THE ANALYSES}

\section{Descriptive analyses}

As PSM is measured on a five-point Likert agreement scale, its aggregate level (3.58) is rather high (see Appendix 2). Looking at the dimensions, mean levels are more diverse: 'Commitment to the public interest' has the highest mean value and 'Selfsacrifice' has the lowest. Such a discrepancy reveals the greater importance of public interest over selflessness for Swiss civil servants at the municipal and cantonal levels.

Results displaying how PSM levels vary according to policy domains are presented in Appendix 3. As all mean differences are significant at an acceptable level, the analysis 
shows that employees working within welfare state missions have the highest level of PSM taken as a whole. Mean differences at the dimensional level provide a more nuanced picture. The highest levels of 'Attraction to politics' and of 'Compassion' are found amongst employees in the welfare domain. This first result was not expected. Conversely, the highest levels of 'Commitment to the public interest' and of 'Self-sacrifice' are found amongst employees working in a policy domain related to the management of infrastructures, environment, and public utilities. Furthermore, civil servants working for the core state functions have the lowest level of 'Compassion'.

Consequently, support for our expectations is mixed: employees working in the welfare sector show the greatest level of 'Compassion' (H1a), but not of 'Commitment to the public interest' (H1b) or 'Self-sacrifice' (H1c), whereas those working in core state functions have the lowest level of 'Compassion' (H2). Finally, those who work in public utilities, environment, and infrastructure sector have, as expected, the highest level of 'Commitment to the public interest' (H3). This result to some extent questions the findings of Leisink and Steijn's (2009) study that showed no significant differences between segments of the Dutch public sector. Considering the Eta ${ }^{2}$, the difference between policy domains exerts a greater effect on 'Compassion'.

Our results on the relation between PSM dimensions and stages of the policy cycle are presented in Appendix 4. First, the highest mean level of aggregated PSM is found among employees who perform political tasks and the lowest is attributed to those in charge of internal services. As testified by the $\mathrm{Eta}^{2}$, this distinction exerts its main effects on the political dimension of PSM. Moreover, mean level differences amongst the different stages of the policy cycle are highly significant for two dimensions ('Attraction to politics' and 'Commitment to the public interest') and are barely significant for the remaining pair. Consequently, those in charge of policy formulation have the highest levels of 'Attraction to politics' and 'Commitment to the public interest'. Therefore, our hypotheses expecting the highest levels of 'Attraction to politics' and 'Commitment to the public interest' to be found within the policy formulation stage ( $\mathrm{H} 4 \mathrm{a}, \mathrm{H} 4 \mathrm{~b})$ are preliminarily supported.

\section{Regression models}

The general models of this study (table 3) provide several interesting results. First, we discuss the association of the socio-demographic and contextual variables to PSM and its four dimensions, and then the relations between policy environment and PSM dimensions.

Results for Model 1 (control variables) confirm most of the previous studies on the individual antecedents of PSM (for an overview and discussion, see Pandey and Stazyk 2008). However, culture and governance level do have an effect on the explanation of PSM and particularly on the 'Commitment to the public interest' dimension (higher score for Swiss-Germans and for municipals).

At first glance, PSM seems to be an attribute of public employees in the welfare sector. But for Models 2 and 3, the distinction between policy domains is significant for all but one dimension of PSM ('Self-sacrifice'), whereas differences in policy stages are significant for two PSM dimensions ('Attraction to politics' and 'Commitment to the public interest'). Hence, 'Compassion' is the PSM dimension that is most influenced by the differences between policy sectors $\left(\Delta \mathrm{R}^{2}=0.028\right)$.

On the other hand, the dimensional results are more significant. In comparison to those working in the general administration, public employees involved in welfare policies are much more inclined to have a strong sense of 'Compassion' (H1a) and to be interested in 


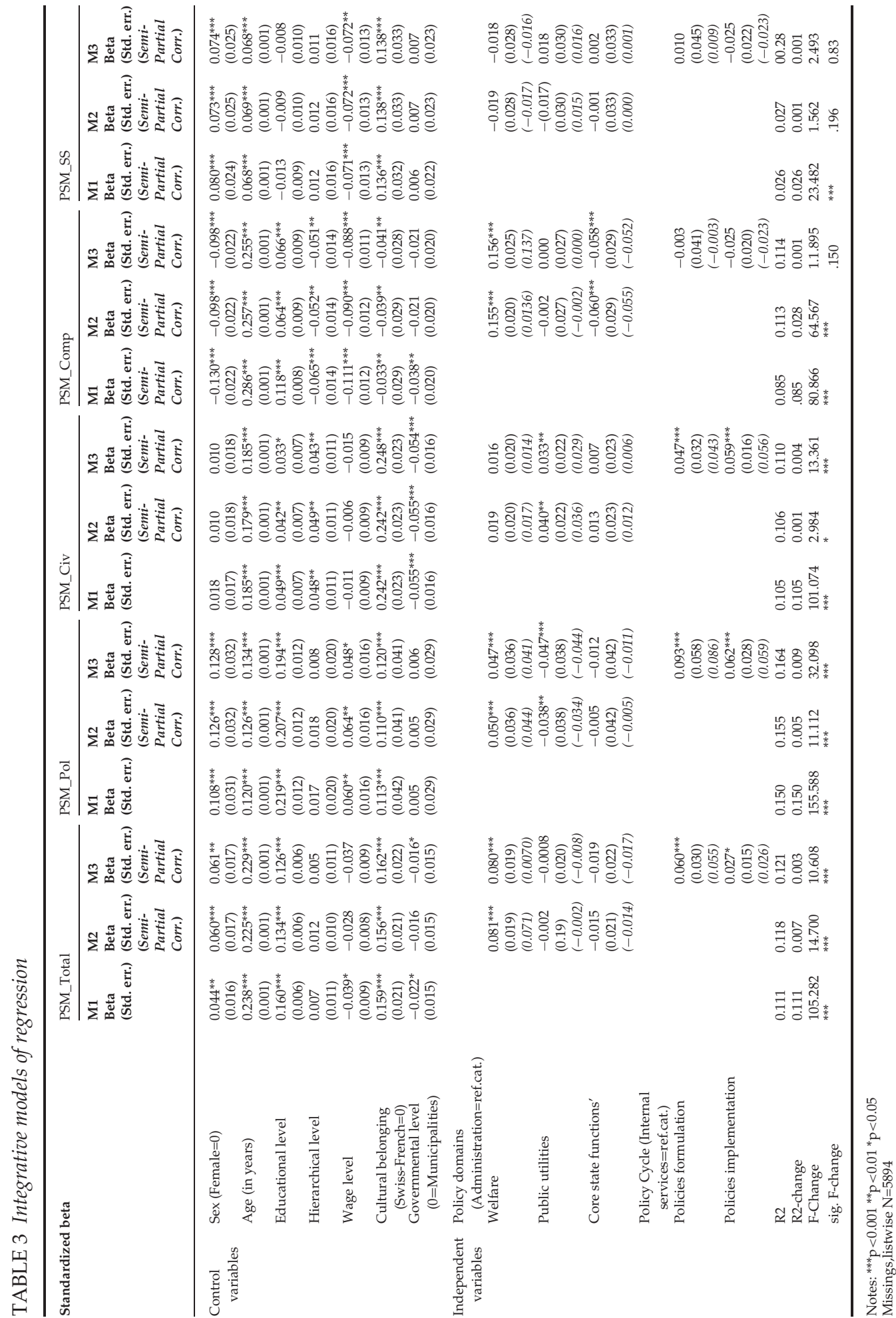


TABLE 4 Assessment of the hypotheses

\begin{tabular}{lllc}
\hline Hypothesis & Confirmed & Mixed & Rejected \\
\hline H1a & X & & \\
H1b & X & & X \\
H1c & X & & \\
H2 & X & & \\
H3 & X & X & X \\
H4a & & & X \\
H4b & & & \\
H5a & & & \\
H5b &
\end{tabular}

political debates. Conversely, those working in core state functions are more likely to be reticent about such empathetic feelings $(\mathrm{H} 2)$. Public servants working on the maintenance of public utilities or infrastructure are clearly committed to the public interest (H3), and are not attracted by politics. Finally, H1c is not supported as 'Self-sacrifice' is not influenced by differences among policy domains, but only by individual and cultural characteristics.

Model 3 tests if and how the inclusion of public employees within a particular stage of the cycle is related to different PSM dimensions. Unsurprisingly, public employees who mainly perform tasks in relation to the formulation of public policies are also those who are most attracted by politics (H4a), but are not particularly committed to the public interest (H4b). The coefficients for the two remaining dimensions ('Compassion' and 'Self-sacrifice') are not significant. The related hypotheses are thus not supported (H5a, $\mathrm{H} 5 b)$.

In summary, the hypotheses regarding policy domains are more supported than the hypotheses regarding policy stages (table 4). Consequently, value alignment or congruency seems to matter more for a given public policy than for specific tasks. Second, the hypotheses grounded in our theoretical frameworks (i.e. P-E fit and ASA) are more systematically supported than those based on previous empirical studies, thus showing the relevance of this analytical framework to understand PSM dynamics, as suggested by Gould-Williams and colleagues in this issue (Gould-Williams et al. 2013). However, the inclusion of the two major dimensions of the policy environment results in low effects size and greater explanatory power. In fact, the purpose of this study was not to include the entire range of PSM antecedents, but to attempt to reintegrate concepts of policy analysis into the academic discussion on PSM.

\section{DISCUSSION AND CONCLUSIONS}

This article relates to studies seeking to uncover the factors underlying the relationship between PSM and employment choice. Its main intention was to analyze how PSM is influenced by 'environmental' variables (i.e. Pandey and Stazyk 2008) by scrutinizing its relationship to different policy sectors and stages of the policy cycle. As a result, the separate dimensions of PSM are not evenly distributed, either among the different missions endorsed by the state in various policy domains, or among the different phases of political action.

For instance, this study indicates who the compassionate public servants are and where they are likely to be found given the pivotal prominence of empathy. Employees who 
have sympathy for the welfare of citizens and whose professional values are imbued with the ethics of care are attracted to jobs in a policy domain that recognizes those other-related values. Conversely, the professional ethic of those in charge of core state functions or prerogative powers by assuming legal power is, rather, based on compliance, norm enforcement, legality, and rationality. By considering both policy sectors and policy stages, our results build upon those of Andersen (2009) who encourages research to uncover the vocational correlates of PSM.

Theoretically, the empirical results indicate that civil servants with PSM-like values are driven by the willingness or need to seek and keep positions within the public sector that are likely to be congruent with their personal aspirations or motivations or, at least, that recognize them. As the Swiss administrative context is not defined by a career system, people who seek jobs in public administrations apply directly for open positions with a sound knowledge of the mission to be undertaken and thus expect a certain level of value congruence.

This latter point has some consequences for agency issues and for the quality of public policies. First, such homogenization could help in solving principal-agent problems by aligning both categories of interests (Gailmard 2010). Second, civil servants' identification with the public policy they work for has a positive effect on its quality (Tummers et al. 2009). Combined with the professionalism perspective, our study attests to the fact that if PSM is not the definite variable explaining policy output, then public service motivated individuals should be considered professionals on whom politicians can rely to execute the task for which they were elected. A greater realization of the common good can be achieved through well-designed public policies.

The present study necessarily has some limitations. First, as in any process of categorization, the reduction of the numerous policy sectors to four general categories is subject to debate. Second, causality issues cannot be avoided, and this is still a major issue in PSM research as noted by several contributors of this volume (i.e. Christensen and Stritch 2013). Do people enter the public sector with PSM values? And is the public sector capable of fostering these values? To solve this chicken-or-egg dilemma, well-designed longitudinal research is required (Wright and Grant 2010). In this study, the public sector is expected to attract PSM-oriented individuals.

More precisely, individuals with different PSM orientations will seek positions (here defined in terms of policy sectors and stages) that will best suit their needs in terms of value congruence. As a result, depending on their public service orientation, civil servants are quite homogeneous groups in terms of their values. In line with the P-E fit and ASA theoretical frameworks, this homogeneity is a consequence of an intertwining of both individuals' attraction to specific work domains and their selection through application processes.

Finally, this study also provides avenues for research to further investigate how the different dimensions of PSM are related to different professions. In that respect, it should be clearly understood that the public sector in general, and the policy environment of civil servants in particular, is characterized by heterogeneity. PSM scholars should thus recognize such complexity at the very least by not treating civil servants as if they were all doing the same job or working in the same policy field. Such an oversimplification is tantamount to equating a teacher with a police officer and expecting them to have the same kinds of professional values and work motivations. 


\section{ACKNOWLEDGEMENTS}

This article is part of a broader research project (no. 100012-116083) financed by the Swiss National Science Foundation. The authors would like to thank the editors and reviewers of Public Administration for their careful reading and helpful comments and suggestions that have contributed to the improvement of the present article. A previous version was presented at the 15th IRSPM Conference in Dublin, 2011.

\section{REFERENCES}

Alonso, P. and G.B. Lewis. 2001. ‘Public Service Motivation and Job Performance: Evidence from the Federal Sector', American Review of Public Administration, 31, 4, 363-80.

Anderfuhren-Biget, S. 2012. 'Profiles of Public Service Motivated Civil Servants: Evidence from a Multicultural Country', International Journal of Public Administration, 35, 1, 5-18.

Anderfuhren-Biget, S., F. Varone, D. Giauque and A. Ritz. 2010. 'Motivating Employees of the Public Sector: Does Public Service Motivation Matter?', International Public Management Journal, 13, 3, 213-46.

Andersen, L.B. 2009. 'What Determines the Behaviour and Performance of Health Professionals? Public Service Motivation, Professional Norms, and/or Economic Incentives', International Review of Administrative Sciences, 75, 1, 79-97.

Bangcheng, L. 2009. 'Evidence of Public Service Motivation of Social Workers in China', International Review of Administrative Sciences, 75, 2, 349-366.

Bright, L. 2005. 'Public Employees With High Levels of Public Service Motivation: Who Are They, Where Are They, and What do They Want?', Review of Public Personnel Administration, 25, 2, 138-54.

Bright, L. 2009. ‘Why Do Public Employees Desire Intrinsic Nonmonetary Opportunities?', Public Personnel Management, 38, 3 , 15-37.

Camilleri, E. 2007. 'Antecedents Affecting Public Service Motivation', Personnel Review, 36, 3, 356-77.

Castaing, S. 2006. ‘The Effect of Psychological Contract Fulfilment and Public Service Motivation on Organizational Commitment in the French Public Utilities', Public Policy and Administration, 21, 1, 84-98.

Cerase, F.P. and D. Farinella. 2009. 'Public Service Motivation: How Does it Relate to Management Reforms and Changes in the Working Situation of Public Organizations? A Case Study of the Italian Revenue Agency', Public Policy and Administration, 24, 3, 281-308.

Christensen, R.K. and J. Stritch. 2013. 'Looking at Job's Social Impact through PSM Tinted Lenses: Probing the Motivation-Perception Relationship', Public Administration.

Clerkin, R.M., S.R. Paynter and J.K. Taylor. 2009. 'Public Service Motivation in Undergraduate Giving and Volunteering Decisions', American Review of Public Administration, 39, 6, 675-98.

Edwards, J., D. Cable, I. Williamson, L. Lambert and A. Shipp. 2006. 'The Phenomenology of Fit: Linking the Person and Environment to the Subjective Experience of Person-Environment Fit', Journal of Applied Psychology, 91, 4, 802-27.

Freeman, G.P. 1985. 'National Styles and Policy Sectors: Explaining Structured Variation', Journal of Public Policy, 5, 4, 467-96.

Gailmard, S. 2010. 'Politics, Principal-Agent Problems, and Public Service Motivation', International Public Management Journal, $13,1,35-45$.

Giauque, D., A. Ritz, F. Varone, S. Anderfuhren-Biget and C. Waldner. 2011. 'Putting Public Service Motivation into Context: A Balance between Universalism and Particularism', International Review of Administrative Sciences, 77, 2, 227-53.

Giauque, D., A. Ritz, F. Varone, and S. Anderfuhren-Biget. 2012. 'Resigned but Satisfied: The Negative Impact of Service Public Motivation and Red Tape on Work Satisfaction', Public Administration, 90, 1, 175-93.

Giauque, D., S. Anderfuhren-Biget, and F. Varone. 2013 'HRM Practices, Intrinsic Motivators and Organizational Performance in the Public Sector', Public Personnel Management.

Gould-Williams, J., P. Bottomley, T. Redman, E. Snape, D. Bishop and T. Limpanitgul. 2013. 'Civic Duty and Employee Outcome: Do High Commitment HR Practices and Work Overload Matter?', Public Administration.

Houston, D.J. and K.E. Cartwright. 2007. 'Spirituality and Public Service', Public Administration Review, 67, 1, 88-102.

Jann, W. and K. Wegrich. 2007. 'Theories of the Policy Cycle', in F. Fischer, G.J. Miller and M. Sidney (eds), Handbook of Public Policy Analysis: Theory, Politics and Methods. Boca Raton, FL: CRC Press, pp. 43-62.

John, P. and A. Cole. 2000. 'When do Institutions, Policy Sectors, and Cities Matter? Comparing Networks of Local Policy Makers in Britain and France', Comparative Political Studies, 33, 2, 248-68.

Jones, C.O. 1984. An Introduction to the Study of Public Policy. Belmont, CA: Wadsworth.

Kim, S. 2006. 'Public Service Motivation and Organizational Citizenship Behavior in Korea', International Journal of Manpower, $27,4,722-40$.

Kim, S. 2009. 'Testing the Structure of Public Service Motivation in Korea: A Research Note', Journal of Public Administration Research and Theory, 19, 4, 839-51. 
Kim, S. 2011. 'Testing a Revised Measure of Public Service Motivation: Reflective versus Formative Specification', Journal of Public Administration Research and Theory, 21, 3, 521-546.

Knoepfel, P., C. Larrue, F. Varone and M. Hill. 2007. Public Policy Analysis. Bristol: The Policy Press.

Leisink, P. and B. Steijn. 2008. 'Recruitment, Attraction, and Selection', in J.L. Perry and A. Hondeghem (eds), Motivation in Public Management: The Call of Public Service. New York: Oxford University Press, pp. 118-35.

Leisink, P. and B. Steijn. 2009. 'Public Service Motivation and Job Performance of Public Sector Employees in the Netherlands', International Review of Administrative Sciences, 75, 1, 35-52.

Levi-Faur, D. 2005. 'The Global Diffusion of Regulatory Capitalism', Annals of the American Academy of Political and Social Science, 598, 1, 12-32.

Lewis, G.B. and S.A. Frank. 2002. 'Who Wants to Work for the Government?', Public Administration Review, 62, 395-404.

Lowi, T.J. 1964. 'American Business, Public Policy, Case-Studies, and Political Theory', World Politics, 16, 4, 677-715.

Majone, G. 1997. 'From the Positive to the Regulatory State: Causes and Consequences of Changes in the Mode of Governance', Journal of Public Policy, 17, 2, 139-67.

Moynihan, D.P. and S.K. Pandey. 2007. 'The Role of Organizations in Fostering Public Service Motivation', Public Administration Review, 67, 1, 40-53.

Naff, K.C. and J. Crum. 1999. 'Working for America: Does Public Service Motivation Make a Difference?', Review of Public Personnel Administration, 19, 4, 5-16.

Pandey, S.K. and E.C. Stazyk. 2008. 'Antecedents and Correlates of Public Service Motivation', in J.L. Perry and A. Hondeghem (eds), Motivation in Public Management: The Call of Public Service. New York: Oxford University Press, pp. 101-17.

Park, S.M. and H.G. Rainey. 2007. 'Antecedents, Mediators, and Consequences of Affective, Normative, and Continuance Commitment: Empirical Tests of Commitment Effects in Federal Agencies', Review of Public Personnel Administration, 27, 3, 197-226.

Perry, J.L. 1996. 'Measuring Public Service Motivation: An Assessment of Construct Reliability and Validity', Journal of Public Administration Research and Theory, 6, 1, 5-22.

Perry, J.L. 1997. 'Antecedents of Public Service Motivation', Journal of Public Administration Research and Theory, 7, 2, 181-97.

Perry, J.L. and A. Hondeghem. 2008. 'Editors' Introduction', in J.L. Perry and A. Hondeghem (eds), Motivation in Public Management: The Call of Public Service. Oxford: Oxford University Press, pp. 1-14.

Perry, J.L. and L.R. Wise. 1990. 'The Motivational Bases of Public Service', Public Administration Review, 50, 3, 367-73.

Perry, J.L., J.L. Brudney, D. Coursey and L. Littlepage. 2008. ‘What Drives Morally Committed Citizens? A Study of the Antecedents of Public Service Motivation', Public Administration Review, 68, 3, 445-58.

Perry, J.L., A. Hondeghem and L.R. Wise. 2010. 'Revisiting the Motivational Bases of Public Service: Twenty Years of Research and an Agenda for the Future', Public Administration Review, 70, 5, 681-90.

Pesch, U. 2008. 'Administrators and Accountability: The Plurality of Value Systems in the Public Domain', Public Integrity, 10, 4, 335-44.

Rainey, H.G. 2009. Understanding and Managing Public Organizations. San Francisco, CA: Jossey-Bass.

Ritz, A. 2011. 'Attraction to Public Policy Making. A Qualitative Inquiry into Improvements in PSM Measurement', Public Administration, 89, 3, 1128-47.

Rouban, L. 1995. 'The Civil Service Culture and Administrative Reform', in B.G. Peters and D.J. Savoie (eds), Governance in a Changing Environment. Montreal: McGill-Queen's University Press, pp. 23-54.

Sabatier, P.A. and H.C. Jenkins-Smith. 1993. Policy Change and Learning: An Advocacy Coalition Approach. Boulder, CO: Westview Press.

Sabatier, P.A. and H.C. Jenkins-Smith. 1999. 'The Advocacy Coalition Framework: An Assessment', in P.A. Sabatier (ed.), Theories of the Policy Process. Boulder, CO: Westview Press, pp. 117-66.

Schneider, B., H.W. Goldstein and D.B. Smith. 1995. 'The ASA Framework: An Update', Personnel Psychology, 48, 4, 747-73.

Schneider, B., D.B. Smith and H.W. Goldstein. 2000. 'Attraction-Selection-Attrition: Toward a Person-Environment Psychology of Organizations', in W.B. Walsh, K.H. Craik and R.H. Price (eds), Person-Environment Psychology: New Directions and Perspectives, 2nd edition. Mahwah, NJ: Erlbaum, pp. 61-85.

Sirkin, R.M. 2006. Statistics for the Social Sciences. Thousand Oaks, CA: Sage Publications.

Steijn, B. 2006. 'Public Service Motivation in the Netherlands', Annual Conference of the EGPA, Public Personnel Policies Study Group, Milan, Italy.

Tummers, L., V. Bekkers and B. Steijn. 2009. ‘Policy Alienation of Public Professionals', Public Management Review, 11, 5, 685-706.

Vandenabeele W. 2007. 'Toward a Public Administration Theory of Public Service Motivation: An Institutional Approach', Public Management Review, 9, 4, 545-56.

Vandenabeele, W. 2008. 'Government Calling: Public Service Motivation as an Element in Selecting Government as an Employer of Choice', Public Administration, 86, 4, 1089-105.

Vandenabeele, W. 2009. 'The Mediating Effect of Job Satisfaction and Organisational Commitment on Self-Reported Performance: More Robust Evidence of the PSM-Performance Relationship', International Review of Administrative Sciences, 75, 1, 11-34. 
Vandenabeele, W. 2011. 'Who Wants to Deliver Public Service? Do Institutional Antecedents of Public Service Motivation Provide an Answer?', Review of Public Personnel Administration, 31, 1, 87-107.

Vandenabeele, W., A. Hondeghem and T. Steen. 2004. 'The Civil Service as an Employer of Choice in Belgium', Review of Public Personnel Administration, 24, 4, 319-33.

Van der Wal, Z. and E.T.J. Van Hout. 2009. 'Is Public Value Pluralism Paramount? The Intrinsic Multiplicity and Hybridity of Public Values', International Journal of Public Administration, 32, 3, 220-31.

Varone, F. 2007. 'The Federal Administration', in U. Klöti, P. Knoepfel, H. Kriesi, W. Linder and Y. Papadopoulos (eds), Handbook of Swiss Politics. Zürich: NZZ Publishing, pp. 289-316.

Vinzant, J.C. 1998. 'Where Values Collide: Motivation and Role Conflict in Child and Adult Protective Services', American Review of Public Administration, 28, 4, 347-66.

Weible, C.M., P.A. Sabatier and K. McQueen. 2009. 'Themes and Variations: Taking Stock of the Advocacy Coalition Framework', Policy Studies Journal, 37, 1, 121-40.

Wright, B.E. 2008. 'Methodological Challenges Associated with Public Service Motivation Research', in J.L. Perry and A. Hondeghem (eds), Motivation in Public Management: The Call of Public Service. New York: Oxford University Press, pp. 80-100.

Wright, B.E. and R.K. Christensen. 2010. 'Public Service Motivation: A Test of the Job Attraction-Selection-Attrition Model', International Public Management Journal, 13, 2, 155-76.

Wright, B.E. and A.M. Grant. 2010. 'Unanswered Questions about Public Service Motivation: Designing Research to Address Key Issues of Emergence and Effects', Public Administration Review, 70, 5, 691-700.

\section{APPENDIX}

\section{Appendix A1 Categories of Policy Domains}

\section{Proposed categories}

Collapsed categories

Health (hospitals, prevention, retirement homes)

Welfare

Social (social subsidies provision, integration, sheltered housing)

Education and youth (schools, youth protection, universities and higher education)

Infrastructure (roads, property holding, information technologies)

Environment (environmental protection, forests, water, town planning and waste management, sustainable development)

Agriculture (veterinary services, viticulture, hunting, and fishing management)

Energy (production, management, marketing and commercialization)

Public transportation and mobility

Security (police, civil and military security, inhabitant control, penitentiary services)

Institutions, legal services and justice (constitution, bankruptcy, judicial proceedings, elections and voting)

Public finances and general administration (chancellery, taxation, human resource management, budgets, controlling)

Public utilities, environment and infrastructure

'Core state functions'

General administration 


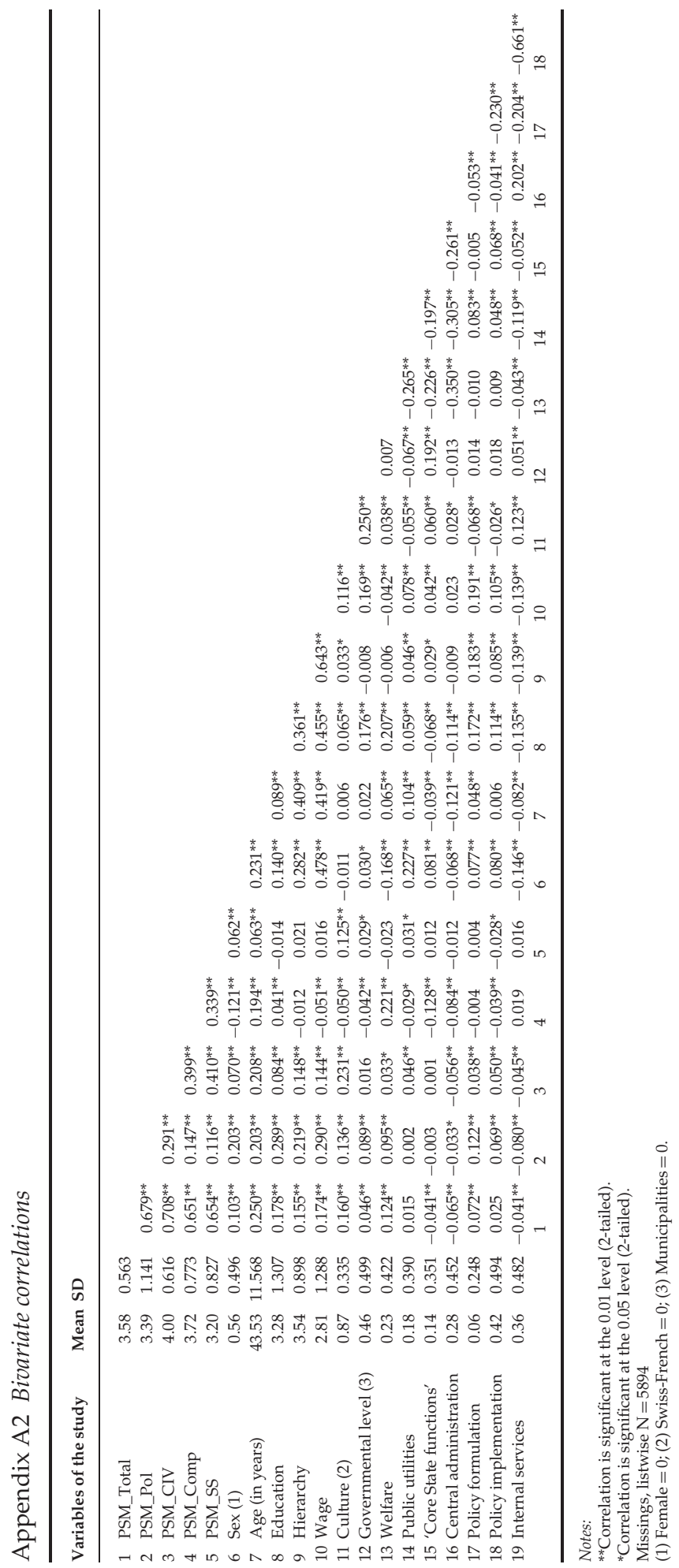


Appendix A3 PSM mean levels, per policy sectors

\begin{tabular}{|c|c|c|c|c|c|c|}
\hline $\begin{array}{l}\text { Sample } \\
(\mathrm{N}=6885)\end{array}$ & Policy sectors & $\begin{array}{l}\text { PSM_Total } \\
\text { Mean (SD) }\end{array}$ & $\begin{array}{l}\text { PSM_Pol } \\
\text { Mean (SD) }\end{array}$ & $\begin{array}{l}\text { PSM_CIV } \\
\text { Mean (SD) }\end{array}$ & $\begin{array}{l}\text { PSM_Comp } \\
\text { Mean (SD) }\end{array}$ & $\begin{array}{l}\text { PSM_SS } \\
\text { Mean (SD) }\end{array}$ \\
\hline & Welfare $(\mathrm{n}=1588)$ & $3.70(0.543)$ & 3.57 (1.108) & $4.03(0.606)$ & $4.03(0.692)$ & $3.17(0.831)$ \\
\hline & $\begin{array}{l}\text { Public utilities, } \\
\text { environment and } \\
\text { infrastructure }(n=1271)\end{array}$ & $3.60(0.573)$ & $3.37(1.123)$ & $4.06(0.615)$ & $3.68(0.777)$ & $3.27(0.860)$ \\
\hline & $\begin{array}{l}\text { Core state functions } \\
\qquad(\mathrm{n}=983)\end{array}$ & $3.51(0.548)$ & $3.35(1.123)$ & $3.98(0.599)$ & $3.47(0.778)$ & $3.22(0.797)$ \\
\hline & $\begin{array}{l}\text { General } \\
\quad \text { administration }(\mathrm{n}=1759)\end{array}$ & $3.51(0.566)$ & $3.30(1.149)$ & $3.93(0.622)$ & $3.62(0.765)$ & $3.18(0.827)$ \\
\hline Total mean & & $3.58(0.564)$ & $3.40(1.140)$ & $3.99(0.614)$ & $3.73(0.777)$ & $3.20(0.831)$ \\
\hline Sig. & & 0.000 & 0.000 & 0.000 & 0.000 & 0.006 \\
\hline Eta & & 0.144 & 0.095 & 0.081 & 0.261 & 0.048 \\
\hline $\mathrm{Eta}^{2}$ & & 0.021 & 0.009 & 0.007 & 0.068 & 0.002 \\
\hline
\end{tabular}

Appendix A4 PSM mean levels, per policy cycle

\begin{tabular}{lllllll}
\hline $\begin{array}{l}\text { Sample } \\
(\mathbf{N = 6 8 8 5})\end{array}$ & Policy cycle & $\begin{array}{c}\text { PSM_Total } \\
\text { Mean (SD) }\end{array}$ & $\begin{array}{c}\text { PSM_Pol } \\
\text { Mean (SD) }\end{array}$ & $\begin{array}{c}\text { PSM_CIV } \\
\text { Mean (SD) }\end{array}$ & $\begin{array}{c}\text { PSM_Comp } \\
\text { Mean (SD) }\end{array}$ & $\begin{array}{c}\text { PSM_SS } \\
\text { Mean (SD) }\end{array}$ \\
\hline & Policy formulation $(n=439)$ & $3.74(0.521)$ & $3.93(1.083)$ & $4.08(0.567)$ & $3.71(0.776)$ & $3.22(0.801)$ \\
& Policy implementation & $3.59(0.556)$ & $3.48(1.105)$ & $4.03(0.615)$ & $3.69(0.778)$ & $3.17(0.823)$ \\
& $\quad(n=2885)$ & & & & & \\
& Internal services (n=2481) & $3.55(0.559)$ & $3.25(1.137)$ & $3.96(0.604)$ & $3.74(0.753)$ & $3.20(0.823)$ \\
Total mean & & $3.58(0.552)$ & $3.41(1.132)$ & $4.00(0.610)$ & $3.71(0.767)$ & $3.20(0.823)$ \\
Sig. & & 0.000 & 0.000 & 0.000 & 0.052 & 0.066 \\
Eta & & 0.088 & 0.163 & 0.068 & 0.032 & 0.031 \\
Eta $^{2}$ & & 0.008 & 0.026 & 0.005 & 0.001 & 0.001 \\
\hline
\end{tabular}

